\title{
FRAGILIZAÇÃO POR HIDROGÊNIO EM PARAFUSOS TEMPERADOS E REVENIDOS COM SUPERFÍCIE CARBONITRETADA ${ }^{1}$
}

\section{Resumo}

Cristiane de Souza Brandolt ${ }^{2}$ Caroline Antunes Corrêa ${ }^{3}$ Felipe Vanti Gonçalves ${ }^{3}$ Roberto Moreira Schroeder ${ }^{4}$ Célia de Fraga Malfatti ${ }^{5}$

Aços com maior teor de boro, como o aço ABNT 10B22-Modificado apresentam maior temperabilidade, o que favorece sua utilização em aplicações onde exista a necessidade de propriedades mecânicas mais elevadas, como em elementos de fixação. Contudo, durante o processo de fabricação desses componentes pode ocorrer entrada de hidrogênio, ocasionando fragilização por hidrogênio, que causa diminuição de propriedades mecânicas tal como diminuição da resistência a tração e da ductilidade. Sendo assim, o presente trabalho avalia a susceptibilidade, quanto à fragilização por hidrogênio, de parafusos fabricados em aço ABNT 10B22-Modificado, com superfície carbonitretada, temperado e revenido a $300^{\circ} \mathrm{C}, 400^{\circ} \mathrm{C}$ e $500^{\circ} \mathrm{C}$. Foram realizados ensaios de tração em corpos de prova sem e com introdução prévia de hidrogênio, que foi realizada a partir de um circuito galvanostático catódico. Também foi realizada a caracterização morfológica das superfícies fraturadas, por microscopia eletrônica de varredura - MEV. Foi observado que todas as amostras com introdução de hidrogênio tiveram diminuição das propriedades mecânicas e apresentaram, nas superfícies de fratura, características mais frágeis em comparação com as amostras sem hidrogênio. Entretanto, dentre as três temperaturas estudadas, as amostras revenidas a $500^{\circ} \mathrm{C}$ sofreram menores efeitos da fragilização por hidrogênio.

Palavras-chave: Fragilização por hidrogênio; Aço ABNT 10B22-Modificado; Revenimento.

\section{HYDROGEN EMBRITTLEMENT ON QUENCHED AND TEMPERED BOLTS WITH CARBONITRIDING SURFACE}

\section{Abstract}

Steels with higher levels of boron, as ABNT 10B22 modified steel have higher hardenability, which favors their use in applications where there is need for higher mechanical properties, such as fastening elements. However, during the manufacturing process of these components can occur hydrogen entry, causing hydrogen embrittlement, which causes decrease of mechanical properties such as reduced tensile strength and ductility. Thus, this study evaluates the susceptibility to hydrogen embrittlement of screws composed of the ABNT10B22 modified steel with carbonitriding on surface, quenched and tempered at $300^{\circ} \mathrm{C}$, $400^{\circ} \mathrm{C}$ and $500^{\circ} \mathrm{C}$. Tensile tests were conducted on specimens with and without introducing previously hydrogen, which was made from a cathodic galvanostatic circuit. Was also performed the morphological characterization of fractured surfaces by scanning electron microscopy - SEM. It was observed that all samples with introduction of hydrogen had mechanical properties decreases and presented on the surfaces of fracture weaker characteristics in comparison with without hydrogen samples. However, among the three temperatures studied, the samples annealed at $500^{\circ} \mathrm{C}$ suffered smaller effects of hydrogen embrittlement.

Key words: Hydrogen embrittlement; Modified ABNT 10B22 steel; Tempering.

1 Contribuição técnica ao $68^{\circ}$ Congresso Anual da ABM - Internacional, 30 de julho a 2 de agosto de 2013, Belo Horizonte, MG, Brasil.

2 Eng. Metalúrgica, Mestranda em Engenharia Metalúrgica, Laboratório de Pesquisa em Corrosão (LAPEC), PPGE3M, UFRGS, Porto Alegre, RS, Brasil.

3 Graduanda em Engenharia Metalúrgica, Laboratório de Pesquisa em Corrosão /LAPEC/ PPGE3M/ UFRGS, Porto Alegre, Brasil.

4 Eng. Metalúrgico, Dr., LAPEC, PPGE3M, UFRGS, Porto Alegre, RS, Brasil.

5 Eng. Metalúrgica, Dra. Professora, LAPEC, PPG3EM, UFRGS, Porto Alegre, RS, Brasil. 


\section{INTRODUÇÃO}

O aço ABNT 10B22-Modificado possui excelente temperabilidade e excelente resposta a processos termoquímicos como cementação e carbonitretação, devido à adição de boro e à presença de um teor elevado de manganês em sua composição química. Com isso, é possível combinar, a este material, propriedades como dureza e resistência ao desgaste com tenacidade e ductilidade. ${ }^{(1,2)}$

Por esta razão, o aço ABNT 10B22-Modificado vem sendo amplamente utilizado, entre outras aplicações, na fabricação de elementos de fixação. Esses por sua vez, sempre foram uma parte muito importante para a indústria mecânica, automobilística, de construção civil, entre outros, encontrando diversas aplicações desde a ligação entre duas partes até sua utilização como multiplicador de esforços. Porém, quando os elementos de fixação são submetidos a diferentes processos como, por exemplo: decapagem, galvanização, eletropolimento, ou ainda, proteção catódica, os mesmos podem sofrer introdução de hidrogênio. ${ }^{(1)}$

$\mathrm{Na}$ forma monoatômica, hidrogênio possui alta mobilidade e procura alojar-se em sítios preferenciais no interior do material. ${ }^{(3,4)}$ Sua presença no interior do aço provoca o fenômeno de fragilização por hidrogênio, um tipo de falha causada pela ação do hidrogênio em combinação com tensões residuais presentes e/ou aplicadas, o que leva a uma redução na plasticidade e capacidade de carga do componente. ${ }^{(5)}$ (5). Os efeitos da fragilização podem ser observados de forma prática nas curvas tensão deformação a partir de reduções da tenacidade, da resistência mecânica e redução ductilidade, o que pode levar o componente à falha prematura. ${ }^{(6)}$

Ao mesmo tempo em que os tratamentos superficiais como carbonitretação aumentam a resistência na superfície, eles também aumentam a susceptibilidade quanto à fragilização por hidrogênio nos materiais, especialmente na região da superfície tratada. Isto ocorre porque aços com maior resistência e maior teor de carbono são muito mais sensíveis ao fenômeno de fragilização por hidrogênio.(7) Desta forma, se esses componentes sofrerem os efeitos da fragilização por hidrogênio, eles podem falhar em uso e causar acidentes catastróficos. ${ }^{\left({ }^{8}\right)}$

No caso de elementos de fixação com roscas, os efeitos ficam agravados, já que a presença de entalhes ativa outros mecanismos de atuação do hidrogênio, relacionados principalmente à tendência que tem o hidrogênio de se acumular na ponta de trincas, entalhes ou fissuras. ${ }^{(4,9)}$ Esses mecanismos acabam promovendo a redução das propriedades mecânicas do componente.

Sendo assim, o estudo do comportamento à tração, com e sem a presença de hidrogênio, em elementos de fixação constituídos do aço ABNT 10B22-Modificado, temperado, revenido e carbonitretado, é importante para compreender os fenômenos relacionados com a ruptura em tração, associada à presença de hidrogênio neste material.

\section{MATERIAL E MÉTODOS}

Neste trabalho estudou-se a influência da presença de hidrogênio em parafusos fabricados em aço ABNT 10B22-Modificado, carbonitretado, temperado e revenido a $300^{\circ} \mathrm{C}, 400^{\circ} \mathrm{C}$ e $500^{\circ} \mathrm{C}$. Para tanto, os parafusos foram submetidas a três níveis de carregamento forçado de hidrogênio através de métodos eletroquímicos e, em seguida, foram submetidas a ensaios de tração com baixas taxas de deformação. As superfícies fraturadas foram caracterizadas quanto à morfologia por microscopia 
eletrônica de varredura. Também foram realizados perfis de microdureza a partir das superfícies das amostras em direção ao núcleo, para amostras em corte transversal.

\subsection{Material Utilizado e Preparação das Amostras}

O material utilizado neste trabalho foi o aço ABNT 10B22-Modificado, cuja composição química está apresentada na Tabela 1. A partir deste material foram fabricados parafusos M4 X 50 (Figura 1) oriundos de um fio de arame 3,40 mm de diâmetro, esferoidizado e retrefilado. Eles passaram pelo processo de estampagem da cabeça sextavada e laminação da rosca, onde o passo de rosca ficou com 0,7mm conforme Norma DIN 13 (10).

Tabela 1. Composição química do aço ABNT 10B22 modificado

\begin{tabular}{|c|c|c|c|c|c|c|c|c|}
\hline Elemento & $\mathrm{C}$ & $\mathrm{Mn}$ & $\mathrm{Cr}$ & $\mathrm{Si}$ & $\mathrm{Al}$ & $\mathrm{B}$ & $\mathrm{P}$ & $\mathrm{S}$ \\
\hline $\begin{array}{c}\text { \% em } \\
\text { massa }\end{array}$ & 0,208 & 1,07 & 0,1369 & 0,237 & 0,029 & 0,0024 & 0,014 & 0,007 \\
\hline
\end{tabular}

Após a usinagem, os corpos de prova passaram pelo processo termoquímico de carbonitretação, seguidos de tempera em óleo e revenimento por $1 \mathrm{~h}$ na temperatura de $300^{\circ} \mathrm{C}, 400^{\circ} \mathrm{C}$ ou $500^{\circ} \mathrm{C}$.

Após o revenimento, as amostras sofreram um tratamento térmico de remoção de hidrogênio difusível a $200^{\circ} \mathrm{C}$ por $10 \mathrm{~h}$.

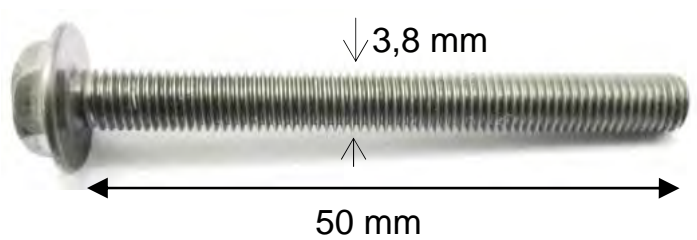

Figura 1. Parafusos utilizado nos ensaios, fabricados conforme Norma DIN 13. (Erro! Indicador não definido.)

\subsection{Introdução Forçada de Hidrogênio}

Os parafusos com diferentes temperaturas de revenido $\left(300^{\circ} \mathrm{C}, 400^{\circ} \mathrm{C}\right.$ e $\left.500^{\circ} \mathrm{C}\right)$ foram submetidos à introdução forçada de hidrogênio, por controle galvanostático, a partir de solução de $2,7 \mathrm{ml} / \mathrm{L}$ de $\mathrm{H}_{2} \mathrm{SO}_{4},(0,1 \mathrm{~N})$ durante 4 horas. Para efeito comparativo, foi conservada uma amostra de cada temperatura de revenido sem carregamento.

A densidade de corrente aplicada foi de $10 \mathrm{~mA} / \mathrm{cm}^{2}$, cuja escolha foi baseada em resultados obtidos em trabalhos anteriores por outros autores. ${ }^{(11)}$ Para a aplicação da corrente escolhida foi utilizado um galvanostato Omnimetria Modelo PG-05. O contra eletrodo utilizado no sistema foi um eletrodo de platina, e um eletrodo de calomelano supersaturado foi empregado como eletrodo de referência.

A Figura 2 mostra uma representação esquemática do circuito utilizado com seus respectivos componentes. Nela é possível observar um amperímetro em série com o contra eletrodo para controle da corrente passante no circuito e, para monitoramento do potencial, um voltímetro está em paralelo com o eletrodo de trabalho e o eletrodo de referência. 


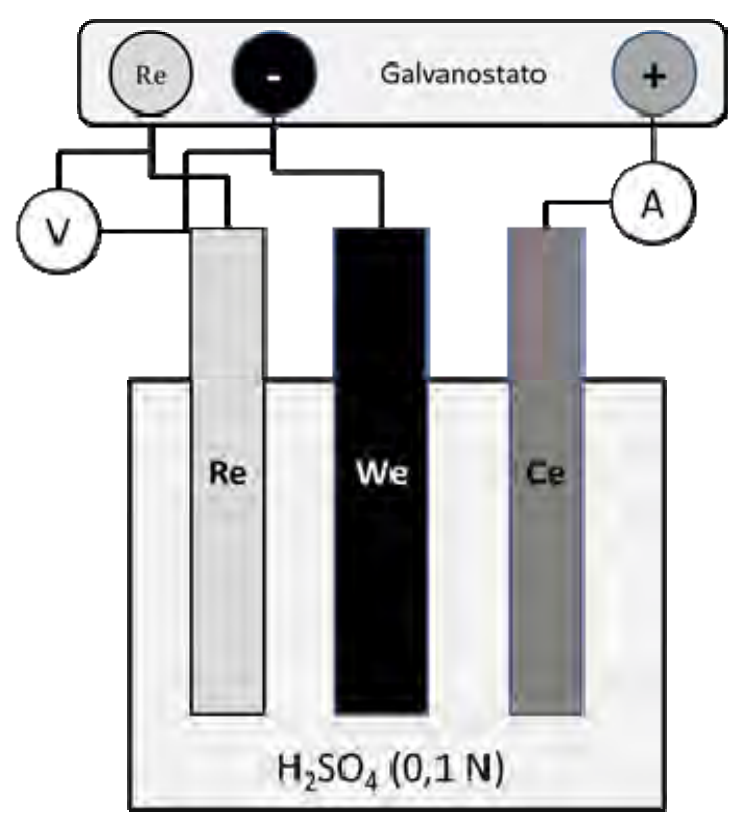

Figura 2. Circuito galvanostático catódico.

\subsection{Caracterização Mecânica}

Após a introdução forçada de hidrogênio, as amostras foram imediatamente submetidas a ensaio de tração ao ar e em temperatura ambiente, em uma máquina de tração universal EMIC, com velocidade de deformação de $1,5 \times 10^{-3} \mathrm{~mm} / \mathrm{min}$.

Esta baixa velocidade de deformação foi escolhida, pois acredita-se que sob altas taxas de deformação não é possível observar os efeitos do hidrogênio nas propriedades mecânicas do material. ${ }^{(12)}$

A Figura 3 apresenta o equipamento utilizado (máquina de tração juntamente com o computador com software para a aquisição de dados) com um corpo de prova sendo ensaiado.

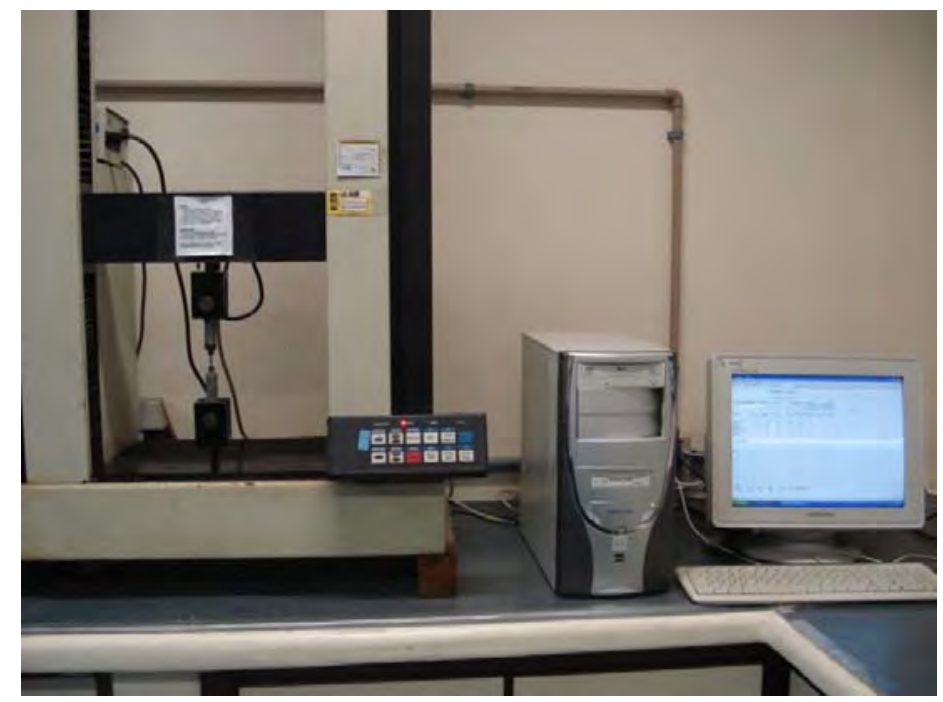

Figura 3. Máquina de ensaio de tração utilizada no trabalho (LAPEC - UFRGS).

Os ensaios de tração também foram realizados nas mesmas condições para os corpos de prova sem introdução forçada prévia de hidrogênio. Para cada condição de amostra (temperatura de revenido e condição de carregamento) estes ensaios 
foram realizados em duplicata ou triplicata dependendo da reprodutibilidade do resultado.

A introdução prévia de hidrogênio e os ensaios de tração foram realizados no Laboratório de Pesquisa em Corrosão (LAPEC) na UFRGS.

\subsection{Caracterização Morfológica}

Após a ruptura das amostras no ensaio de tração, as mesmas foram conduzidas para caracterização da morfológica das fraturas em um microscópio eletrônico de varredura (MEV) Jeol JSM 6060, operando com 20kV. As imagens de MEV foram obtidas no Centro de Microscopia da UFRGS.

O objetivo principal desta caracterização é analisar os aspectos das fraturas e correlacionar cada aspecto com a presença ao não de hidrogênio no material.

As imagens foram obtidas na região superficial das amostras onde ocorreu 0 tratamento termoquímico de carbonitretação e no núcleo, onde as peças estavam somente temperadas e revenidas.

\section{RESULTADOS}

\subsection{Ensaios Mecânicos}

A Figura 4 apresenta os resultados dos ensaios de tração com baixa taxa de deformação para as amostras revenidas a $300^{\circ} \mathrm{C}$, onde é possível fazer um comparativo entre a amostra com carregamento e sem carregamento prévio de hidrogênio. Já nas Figuras 56 são exibidas curvas de tração dos parafusos revenidos a $400^{\circ} \mathrm{C}$, também comparando as situações ciom e sem hidrogênio préviamente introduzido. Para esta condição de revenimento, são apresentadas duas curvas pois este material apresentou diferentes comportamentos frente a fragilização por hidrogênio.

Na Figura 7 são exibidas curvas tensão $x$ deformação dos parafusos revenidos a $500^{\circ} \mathrm{C}$ com e sem carregamento prévio de hidrogênio.

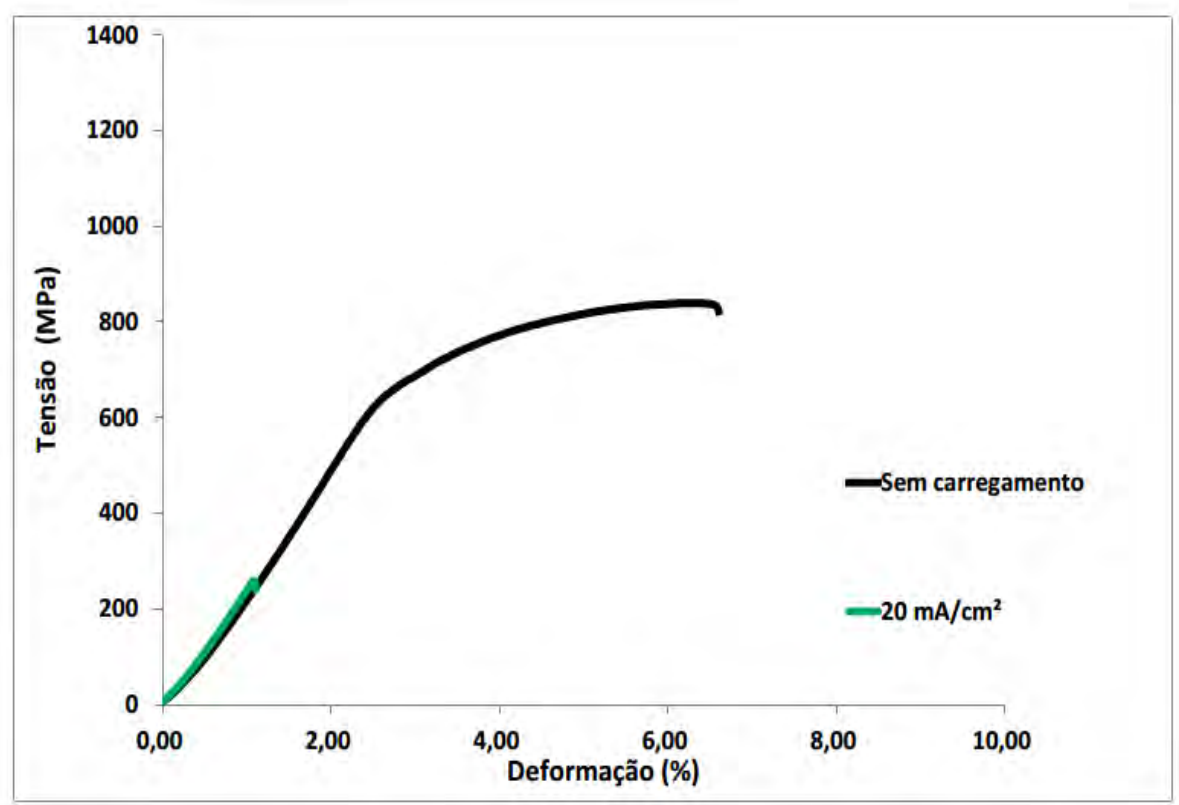

Figura 4. Curva Tensão X Deformação para os parafusos revenidos a $300^{\circ} \mathrm{C}$. 


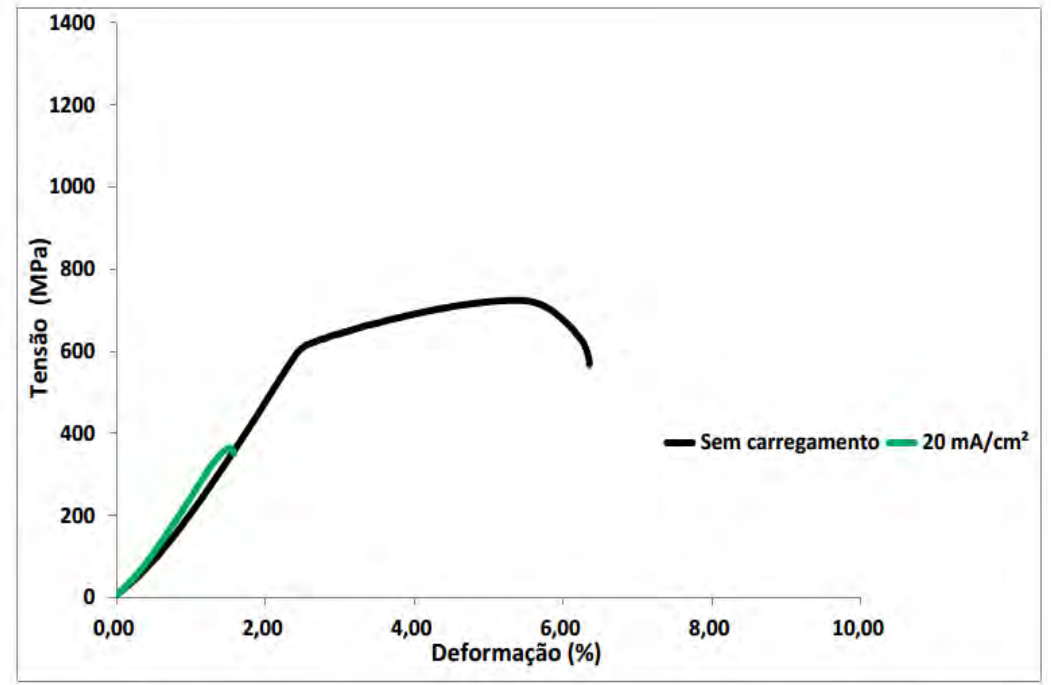

Figura 5. Curva Tensão $X$ Deformação para os parafusos revenidos a $400^{\circ} \mathrm{C}$ com comportamento próximo aos parafusos revenidos a $300^{\circ} \mathrm{C}$.

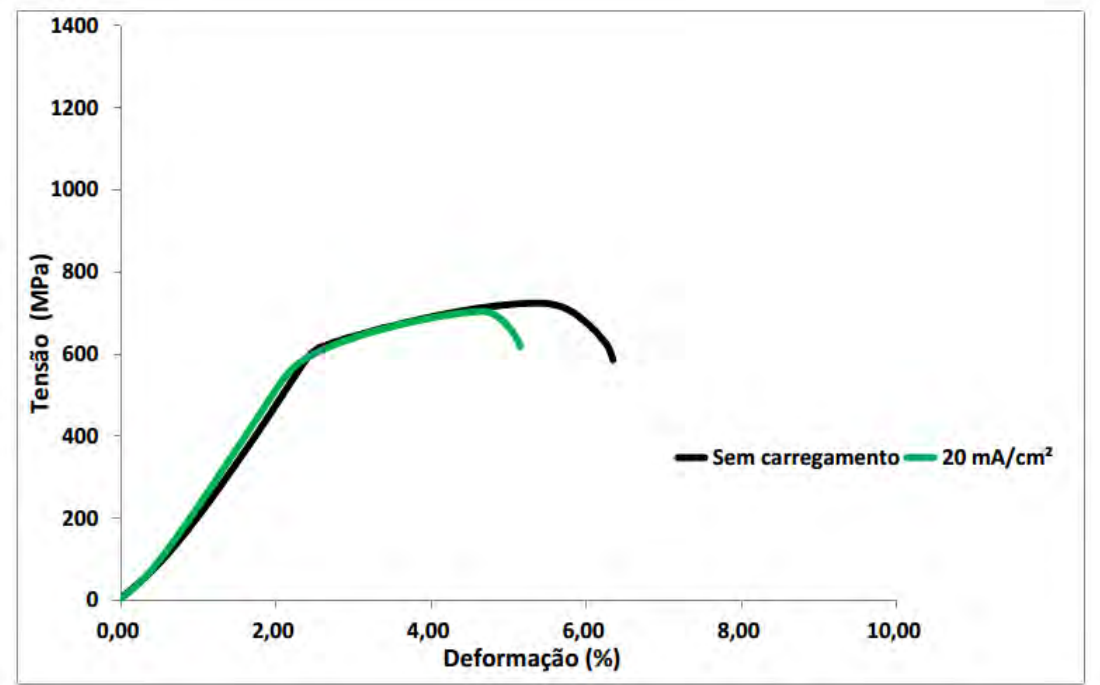

Figura 6. Curva Tensão $X$ Deformação para os parafusos revenidos a $400^{\circ} \mathrm{C}$ com comportamento próximo aos parafusos revenidos a $500^{\circ} \mathrm{C}$.

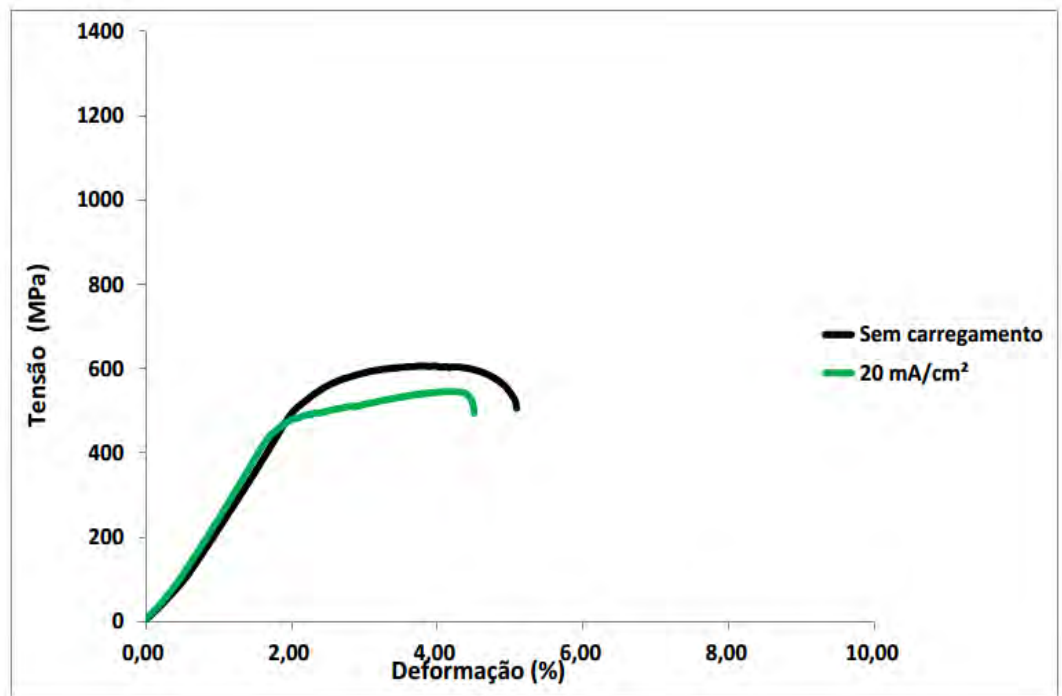

Figura 7. Curva Tensão X Deformação para os parafusos revenidos a $500^{\circ} \mathrm{C}$. 


\subsection{Caracterização Morfológica}

A Figura 8 mostra a morfologia das fraturas na região da superfície carbonitretada dos corpos de prova, obtidas por microscopia eletrônica de varredura para as três temperaturas de revenimento, com e sem carregamento. A partir da Figura 9 é possível observar a superfície de fratura, na região do núcleo dos corpos de prova, para as mesmas condições mencionadas anteriormente.

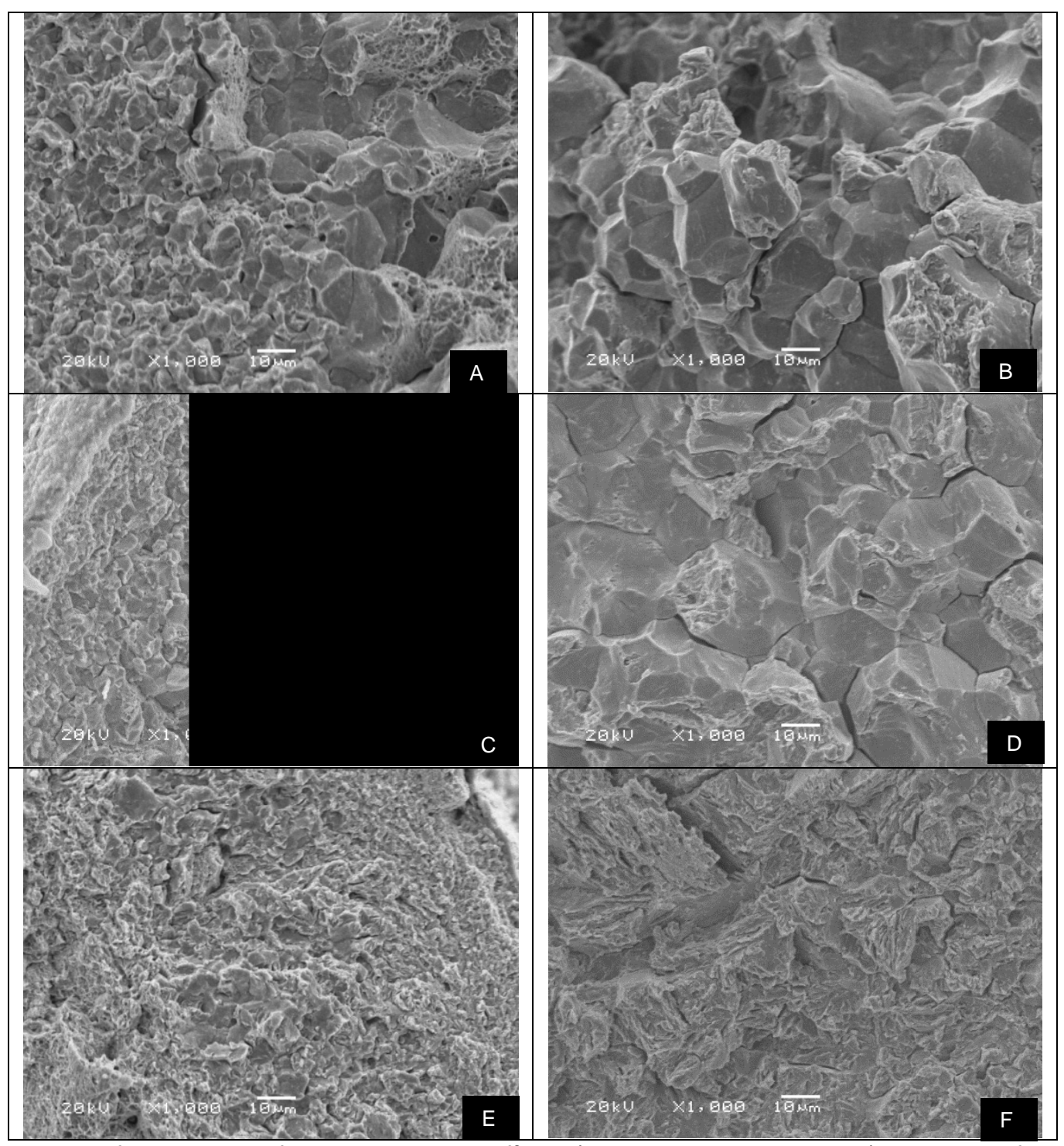

Figura 8. Morfologia das fraturas na superfície (camada carbonitretada) dos parafusos nas condições: (a) $300^{\circ} \mathrm{C}$ sem carregamento, (b) $300^{\circ} \mathrm{C}$ com carregamento, (c) $400^{\circ} \mathrm{C}$ sem carregamento, (d) $400^{\circ} \mathrm{C}$ com carregamento, (e) $500^{\circ} \mathrm{C}$ sem carregamento, (f) $500^{\circ} \mathrm{C}$ com carregamento. MEV. 


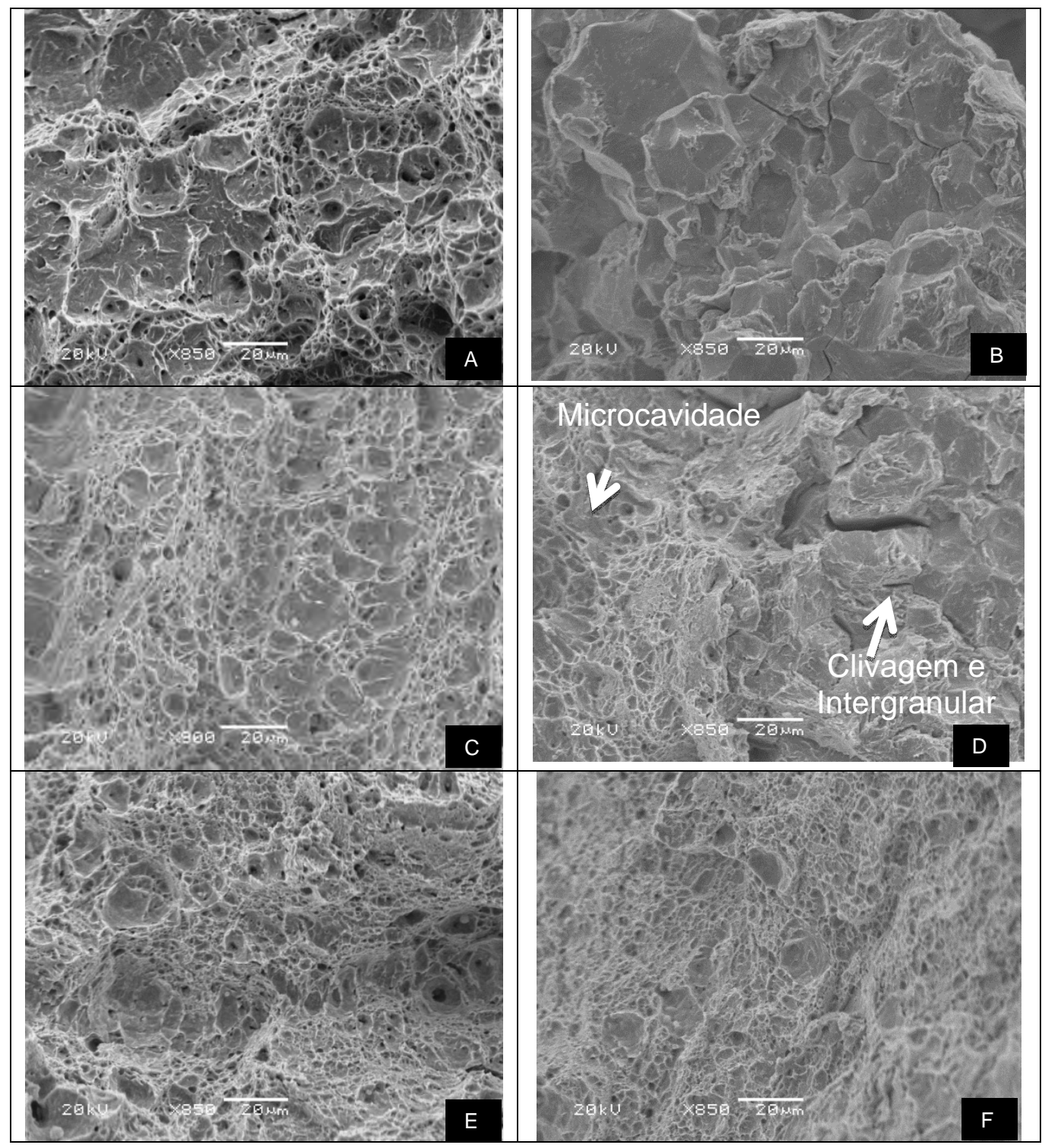

Figura 9. Morfologia das fraturas no núcleo dos parafusos nas condições: (a) $300^{\circ} \mathrm{C}$ sem carregamento, (b) $300^{\circ} \mathrm{C}$ com carregamento, (c) $400^{\circ} \mathrm{C}$ sem carregamento, (d) $400^{\circ} \mathrm{C} \mathrm{com}$ carregamento, (e) $500^{\circ} \mathrm{C}$ sem carregamento, (f) $500^{\circ} \mathrm{C}$ com carregamento. MEV.

\section{DISCUSSÃO DOS RESULTADOS}

\subsection{Ensaios Mecânicos}

Para as amostras revenidas a $300^{\circ} \mathrm{C}$ (Figura 4), observa-se um importante decréscimo da resistência a tração e do alongamento, comparando-se a amostra sem carregamento com a amostra com carregamento prévio de hidrogênio. A queda acentuada nas propriedades mecânicas dos parafusos carregados a $300^{\circ} \mathrm{C}$ pode estar relacionada à baixa temperatura de revenimento, o que aumenta a concentração de tensões no interior peça, tornando estes locais preferenciais para a ação deletéria do hidrogênio. Outros autores ${ }^{(13)}$ avaliaram a susceptibilidade à fragilização por hidrogênio de um aço SAE 1050 temperado e revenido em diferentes temperaturas, e concluiram que para menores temperaturas de revenimento a estrutura martensítica é mais suscetível ao fenômeno de fragilização por hidrogênio. 
Os parafusos revenidos a $400^{\circ} \mathrm{C}$ (Figuras 5 e 6) com carregamento não apresentaram boa reprodutibilidade nas duplicatas, por isso, nesta temperatura de revenimento os ensaios foram realizados em triplicata. Foi possível observar que nesta condição de revenimento, os parafusos algumas vezes apresentavam comportamento próximo aos parafusos revenidos a $300^{\circ} \mathrm{C}$ (Figura 4), e outras vezes apresentavam comportamento semelhante aos parafusos revenidos a $500^{\circ} \mathrm{C}$ (Figura 7).

Estes desempenhos irregulares dos parafusos carregados e revenidos nesta temperatura se mantiveram durante todos os ensaios realizados. A instabilidade apresentada pode estar relacionada a uma série de fatores, como por exemplo, a impossibilidade de lixar e polir a rosca, alguma instabilidade dimensional no diâmetro interno do parafuso, entre outros fatores referentes ao parafuso, pois nos corpos de prova lisos a repetitividade foi muito boa. Porém, como este comportamento foi verificado apenas nos parafusos carregados com hidrogênio e revenidos a $400{ }^{\circ} \mathrm{C}$, outros fatores como tamanho e distribuição de carbonetos e/ou da martensita revenida nesta temperatura também podem colaborar para que tal fato tenha ocorrido, o que sugere uma futura pesquisa mais aprofundada a fim de esclarecer melhor o comportamento instável apresentado nesta condição.

Mesmo oscilando bastante, os resultados apresentados na condição com carregamento, podem ser considerados intermediários entre as outras condições de revenimento $\left(300^{\circ} \mathrm{C}\right.$ e $\left.500^{\circ} \mathrm{C}\right)$, com uma melhora da tenacidade e da resistência a tração em relação à amostra carregada na temperatura de $300^{\circ} \mathrm{C}$.

A partir da Figura 6, é possível observar, para as amostras revenidas a $500^{\circ} \mathrm{C}$, que em relação ao parafuso na condição inicial, a amostra com carregamento não apresentou decréscimo significativo nas propriedades de alongamento, tenacidade e resistência à tração, comparativamente à amostras revenidada nessa temperatura, sem carregamento.

O revenimento é um tratamento térmico que tem como um de seus principais objetivos remover as tensões internas da peça, então era esperado que o aumento da temperatura de revenimento diminuísse as tensões residuais no material e aumentando a tenacidade do mesmo, ${ }^{(14)}$ promovendo dessa forma uma menor susceptibilidade a fragilização por hidrogênio quando comparado aos outros sistemas estudados (temperaturas de revenimento de $300^{\circ} \mathrm{C}$ e $500^{\circ} \mathrm{C}$ ).

\subsection{Caracterização Morfológica}

A partir da Figura 8, observa-se que na região da camada carbonitretada, a superfície de fratura dos parafusos revenidos a $300^{\circ} \mathrm{C}$ (Figura 8a) apresentou um misto de clivagem, coalescência de microcavidades e fratura intergranular na amostra sem carregamento de hidrogênio, enquanto que com a presença de hidrogênio (Figura 8b), a aparência de fratura passou a totalmente intergranular. Este comportamento é característico da fragilização por hidrogênio, uma vez que os contornos de grão são um caminho preferencial para a difusão do hidrogênio e favorecem dessa forma a propagação de trincas, pois o hidrogênio é segregado nos contornos de grão reduzindo sua energia coesiva. ${ }^{(15)}$

Esta região apresentou as mesmas características nos parafusos revenidos a $400^{\circ} \mathrm{C}$ (Figura 8c e Figura 8d), tanto para as amostras que tiveram comportamento dúctil quanto para as amostras com comportamento frágil.

A camada carbonitretada tem seu percentual de carbono aumentado até valores entre $0,8 \%$ e 0,9\%, o que proporciona neste local uma maior dureza e resistência ao 
desgaste ${ }^{(16)}$ porém, esta região também fica mais suscetível aos micromecanismos de fratura frágil conforme observado, principalmente para temperaturas mais baixas de revenimento.

Já os parafusos revenidos a $500^{\circ} \mathrm{C}$ apresentaram pouca alteração em relação à fratura da camada superficial, tendo em coalescimento de microcavidades a sua principal característica tanto na condição sem carregamento (Figura 8e), como na condição com carregamento de hidrogênio (Figura 8f). Esse fato vem ao encontro dos outros resultados apresentados, em que a estrutura formada na temperatura de revenido de $500^{\circ} \mathrm{C}$ é a menos afetada pela presença do hidrogênio.

Conforme se observa na Figura 8 , o parafuso revenido a $300^{\circ} \mathrm{C}$ sem carregamento (Figura 9a) apresentou uma fratura mista de clivagem e coalescência de microcavidades na região do núcleo. Com o carregamento (Figura 9b), a fratura nesta condição de revenido passou a ter o aspecto frágil, com muitas regiões de fratura intergranular e clivagem. Mesmo a região do núcleo apresentando um menor teor de carbono, a influência da introdução forçada de hidrogênio também se mostrou acentuada, provavelmente devido à geometria dos parafusos e a maior facilidade do hidrogênio ingressar nesse tipo de componente, comprometendo o desempenho dos parafusos revenidos nessa temperatura quanto às propriedades mecânicas.

Quanto aos parafusos revenidos a $400^{\circ} \mathrm{C}$, as amostras com carregamento, apresentaram bastante variação nos mecanismos de fratura, apresentando às vezes comportamento dúctil (microcavidades), e outras vezes um comportamento frágil (clivagem e intergranular). A partir da Figura 9d é possível observar esta variação de comportamento de fratura, onde na região à esquerda da imagem tem-se microcavidades e do lado oposto um misto de fratura intergranular e clivagem, conforme indicado por setas. Este comportamento está provavelmente relacionado a heterogeneidade deste material revenido nesta temperatura, o que está de acordo com os resultados obtidos nas curvas tensão deformação.

Os parafusos revenidos a $500^{\circ} \mathrm{C}$ (Figuras 9e e 9f) apresentaram fratura dúctil em todas as condições de carregamento, tendo apenas alguns dimples mais rasos para as amostras com carregamento prévio de hidrogênio. Este resultado observado par os parafusos revenidos a $500^{\circ} \mathrm{C}$ é semelhante aos resultados encontrados no trabalho de Shibata, Takashi e Tsuji, ${ }^{(17)}$ onde o carregamento com hidrogênio foi realizado em aços martensíticos de baixo carbono e observou presença de microcavidades na superfície de fratura.

\section{CONCLUSÃO}

- As propriedades mecânicas nos parafusos constituídos do aço ABNT 10B22Modificado foram afetadas pelo carregamento com hidrogênio, principalmente para temperaturas mais baixas de revenimento;

- as imagens das regiões fraturadas evidenciaram que houve alteração no modo de fratura das amostras com carregamento prévio de hidrogênio, quando comparadas às amostras sem carregamento. Sendo que as amostras carregadas apresentaram características mais frágeis que as amostras sem carregamento;

- a região da camada carbonitretada teve como micromecanismo predominante de falha a fratura intergranular, para as amostras com carregamento prévio com hidrogênio; 
- na região do núcleo das amostras com carregamento o comportamento variou bastante, sendo que nas amostras revenidas a $300^{\circ} \mathrm{C}$ apresentaram micromecanismo de fratura intergranular, enquanto as revenidas a $500^{\circ} \mathrm{C}$ apresentaram micromecanismo de fratura por microcavidades e as amostras revenidas a $400^{\circ} \mathrm{C}$ apresentaram comportamento misto, com presença de microcavidades, clivagem e fratura intergranular;

- os parafusos revenidos a $300^{\circ} \mathrm{C}$ apresentaram importantes reduções de propriedades mecânicas, apresentando acentuada diminuição da resistência à tração e da ductilidade;

- os parafusos revenidos a $400^{\circ} \mathrm{C}$ tiveram comportamento variável, aproximando-se às vezes do comportamento observado para os parafusos revenidos a $300^{\circ} \mathrm{C}$, e outras vezes do comportamento observado para os componentes revenidos a $500^{\circ} \mathrm{C}$; e

- em termos de propriedades mecânicas o aço ABNT 10B22-Modificado, revenido a $500^{\circ} \mathrm{C}$ apresentou a estrutura metalúrgica menos susceptível à fragilização pelo hidrogênio.

\section{Agradecimentos}

Os autores agradecem o apoio financeiro da Capes, do CNPq e da FAPERGS.

\section{REFERÊNCIAS}

1 MODIANO, S.; CARREÑO, J. A.; FUGIVARA, C. S.; BENEDETTI, A. V.. Effect of hydrogen charging on the stability of SAE 10B22 steel surface in alkaline solutions. Electrochimica Acta, Brazil, v. 51, n. 4, p.641-648, nov. 2005.

2 GONÇALVES F. V., BRANDOLT C. S., SCHROEDER R. M., MALFATTI C. F., Avaliação da Influência da Temperatura de Revenido na Fragilização por Hidrogênio do Aço ABNT 10B22 Modificado, Intercorr 2012, Salvador - Ba, 2012.

3 CARTER, T.J. ; CORNISH, L.A. Hydrogen in Metals. Engineering Failure Analysis, v. 8, p. 113-121, 2001.

4 ĆWIEK, J. Prevention methods against hydrogen degradation of steel. Journal of Achievements In Materials And Manufacturing Engineering, Poland, v. 43, n. 1, p.214-221, nov. 2010.

5 AMERICAN SOCIETY FOR TESTING AND MATERIALS. ASTM F2078-08a: standard terminology relating to hydrogen embrittlement testing. West Conshohocken, Pennsylvania, United States of America, 2008. 4p.

6 BRANDOLT C. S., Susceptibilidade à fragilização pelo hidrogênio do aço ABNT 10B22 modificado submetido a diferentes temperaturas de revenido. Trabalho de conclusão de curso, p.27-33, Brasil, 2012.

7 LEE S., RONEVICH J. A., KRAUSS G. e MATLOCK D. K. Hydrogen Embrittlement of Hardened Low-carbon Sheet Steel, ISIJ International, Vol. 50, No. 2, pp. 294-301. 2010.

8 BRANDOLT C. S., GONÇALVES F. V., KORB M. A., SCHROEDER R. M., MALFATTI C. F Efeito da fragilização por hidrogênio no aço abnt 10b22 modificado carbonitretado temperado e revenido a $400^{\circ} \mathrm{C} .67^{\circ}$ Congresso Internacional da ABM, VER PGS NOS ANAIS, Rio de Janeiro, Brasil, 2012.

9 GEMELLI E. Corrosão de materiais metálicos e sua caracterização. LTC, p66-68, Brasil, 2001. 
10 DIN 13-1 - ISO. General purpose metric screw threads - Part 1: Nominal sizes for coarse pitch threads; nominal diameter from $1 \mathrm{~mm}$ to $68 \mathrm{~mm}, 1999$.

11 NAGU, G ANANTA; NAMBOODHIRI, T K G. Effect of heat treatments on the hydrogen embrittlement susceptibility of API X-65 grade line-pipe steel. Bulletin Of Materials Science, India, v. 26, n. 4, p.435-439, jun. 2003.

12 MUKHOPADHYAY, N.K.; SRIDHAR, G.; PARIDA, N; TARAFDER, S; RANGANATH, V.R.. Hydrogen embrittlement failure of hot dip galvanised high tensile wires.

Engineering Failure Analysis, India, v. 6, n. 4, p.253-265, 01 ago. 1999.

13 AMRIN, A.; BAKAR, Y.A. A Study of Hydrogen Embrittlement on Tempered Carbon Steel. Jurnal Mekanikal, Jilid1: Malásia, 1996.

14 KWIETNIEWSKI, C. E. F., KISS, F. J. Metalografia e Tratamentos Térmico de Aços e Ferros Fundidos. Porto Alegre. 2011.

15 EBIHARA, K.; ITAKURA, M.; YAMAGUCHI., M.; KABURAKI., H.; SUZUDO, T. Evaluation of Stress and Hydrogen Concentration at Grain Boundary of Steels Using Three-Dimensional Polycrystalline Model. Nuclear Science and Technology, Japan, v. 2, p. $38-43,2011$

16 PRABHUDEV, K. H. Handbook of heat treatment of steels. New Delphi: Tata McGrawHill Publishing Compan Limited, 2008. p. 386-387. Disponível em: http://books.google.com.br. Acesso em: nov.2012.

17 SHIBATA, Akinobu; TAKAHASHI, Hiroshi; TSUJI, Nobuhiro. Microstructural and Crystallographic Features of Hydrogenrelated Crack Propagation in Low Carbon Martensitic Steel. ISIJ International, v. 52, n.. 2, p. 208-212, 2012. 